\title{
ChemComm
}

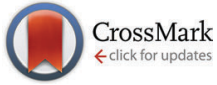

Cite this: Chem. Commun., 2015, 51,10854

Received 15th April 2015,

Accepted 31st May 2015

DOI: $10.1039 / \mathrm{c} 5 \mathrm{cc03130c}$

www.rsc.org/chemcomm

\section{Stereoselective formation of coordination polymers with 1,4-diaminonaphthalene on various Cu substrates $\dagger$}

\author{
Marek Knor, ${ }^{a b}$ Hong-Ying Gao, ${ }^{\text {ab }}$ Saeed Amirjalayer, ${ }^{\text {ab }}$ Armido Studer, \\ Hongjun Gao, ${ }^{d}$ Shixuan Du ${ }^{d}$ and Harald Fuchs ${ }^{\text {abe }}$
}

\begin{abstract}
Polymerization of 1,4-diaminonaphthalene on various $\mathrm{Cu}$ substrates resulting in stereoselectively well-defined metal-organic coordination polymers is reported. By using different crystallographic planes (111), (110) and (100) of a Cu substrate the structure of the resulting coordination polymer was controlled.
\end{abstract}

On-surface polymerization has recently been used as an efficient method for the preparation of well defined, novel types of polymers directly at a surface. Many contributions in this area deal with on-surface covalent carbon-carbon or carbon-nitrogen bond formation. ${ }^{1}$ In addition, this approach has also been successfully applied to the formation of metal-organic polymers containing carbon-metal ${ }^{2}$ or nitrogen-metal coordination bonds. ${ }^{3}$ In the latter cases, a metal atom is either added to or extracted from the surface during polymerization. It is well known that the surface is not static (especially above room temperature) and some of the metal atoms can be readily pulled out from the surface and be ligated by the organic adsorbate. ${ }^{4}$ Metal-organic coordination polymers are highly interesting because they show unique properties. Considering structural properties, either $3 \mathrm{D}$ or $2 \mathrm{D}$ coordination frameworks can be constructed at the surface. Moreover, such surface adsorbed coordination networks reveal interesting catalytic, ${ }^{5}$ magnetic ${ }^{6}$ and electronic $^{7}$ properties. It is obvious that all these properties are influenced and controlled by the structure and geometry of the coordination polymer. Another aspect is that the electronic configuration of the coordination center (metal atom) in such networks is not readily predictable. The metal can have different oxidation states

\footnotetext{
${ }^{a}$ Center for Nanotechnology, Heisenbergstraße 11, 48149 Münster, Germany. E-mail:mknor01@uni-muenster.de,gaoh@uni-muenster.de, fuchsh@uni-muenster.de ${ }^{b}$ Physikalisches Institut, Westfälische Wilhelms-Universität, Wilhelm-Klemm-Straße 10, 48149 Münster, Germany

'Organisch-Chemisches Institut, Westfälische Wilhelms-Universität, Corrensstraße 40, 48149 Münster, Germany

${ }^{d}$ Institute of Physics, Chinese Academy of Sciences, Beijing 100190, China

${ }^{e}$ Institute for Nanotechnology, Karlsruhe Institute of Technology, 76344 Karlsruhe, Germany

$\dagger$ Electronic supplementary information (ESI) available. See DOI: 10.1039/ c5cc03130c
}

and charges because the surface works as an electron reservoir which can interact with the organometallic complex at the surface. ${ }^{8}$ In specific cases the electronic configuration of the complex at the surface is different as compared to its electronic state in solution and in the solid state. For example, a $\mathrm{Cu}$ adatom on a $\mathrm{Cu}(111)$ substrate can be negatively charged when it is bonded to a cyano group. ${ }^{4 d}$ It is obvious that complexes interacting with a substrate might show different catalytic activity. Therefore, understanding the geometry of coordination systems at a surface within the 2D network and also its interaction with the substrate is of great importance for future application of these systems, for example in catalysis. Here, we report the effect of the substrate reconstitution on the final geometry of the coordination network and show that different crystallographic structures of the same metal (in this case $\mathrm{Cu}$ ) control the stereochemistry of polymerization leading to coordination polymers with different relative configurations.

Polymerization of 1,4-diaminonaphthalene at $\mathrm{Cu}(111)$ : evaporation of 1,4-diaminonaphthalene (DAN) at the $\mathrm{Cu}(111)$ substrate at room temperature leads to formation of monolayers where the organic molecules are randomly distributed showing different orientations on the surface. The random orientation of DANs indicates that the interaction between the organic molecules is weaker than the one between DANs and the Cu-substrate. After heating the sample to $390 \mathrm{~K}$ most of the molecules just desorbed but we also observed the formation of some dimers which were found to be very mobile at the surface under applied conditions. These dimers and remaining monomers upon further heating of the surface to $400 \mathrm{~K}$ started to form longer oligomers. This process was slow and not very efficient due to low concentration of monomers and dimers caused by the competing thermal desorption. Better results were obtained by depositing DANs directly at a hot $\mathrm{Cu}(111)$ surface. This process allowed the desorbed diaminonaphthalenes to be continuously recharged to the surface which can diffuse and react with oligomers leading to a further growth of the polymers (Fig. 1a). By using this set up, oligomers with a chain length of up to $20 \mathrm{~nm}$ were formed. It is clearly visible from the STM images that most polymers grew along one of the three main crystallographic axes of the substrate. The $\mathrm{Cu}-\mathrm{N}$ bond in the $\mathrm{Cu}-$-complex was found to be very stable. 

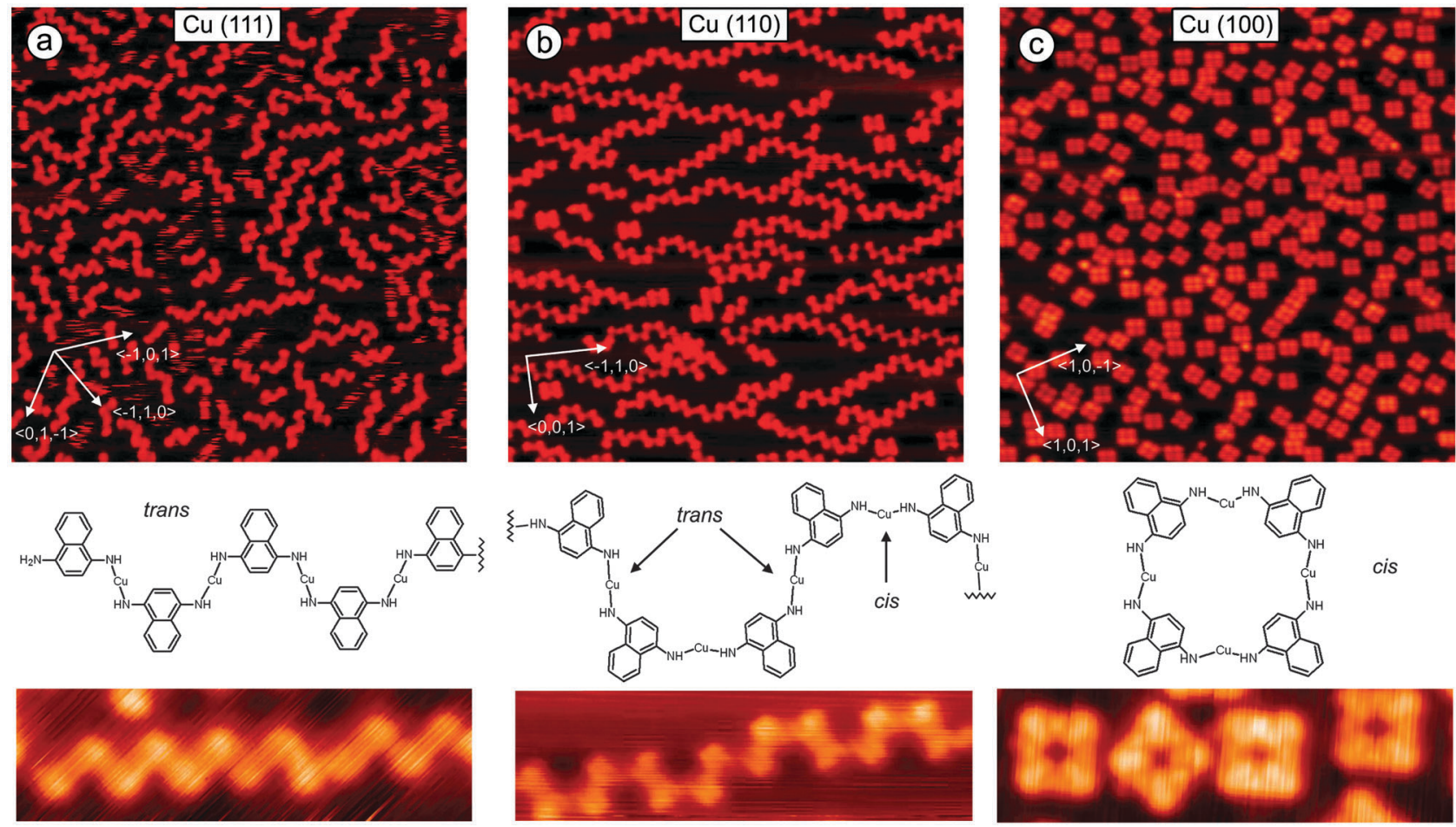

Fig. 1 Polymers formed after deposition of DAN at a hot Cu(111) substrate (a) $45 \times 45 \mathrm{~nm}^{2}$, Cu(110) substrate (b) $45 \times 45 \mathrm{~nm}{ }^{2}$ and Cu(100) substrate (c) $45 \times 45 \mathrm{~nm}^{2}$. STM pictures a-c: $-2 \mathrm{~V}, 10 \mathrm{pA}$. Below proposed chemical structures of the dominant polymers fractions for each substrate and zoom in of the corresponding single chains.

The amino ligands are trans-oriented to each other as a naphthyl$\mathrm{NH}-\mathrm{Cu}-\mathrm{NH}-$ naphthyl complex. Note that dehydrogenation in amines is known to occur at $\mathrm{Cu}(111)$ and at $\mathrm{Au}(111)$ substrates. ${ }^{9}$ Importantly, while in solution bisamino- $\mathrm{Cu}$ bonds can rotate around the $\mathrm{Cu}-\mathrm{N}-$ bond, due to van der Waals interactions with the substrate free rotation is suppressed at the $\mathrm{Cu}$ surface. Therefore, $\mathrm{Cu}$-amino complexes can be formed as different stereoisomers at $\mathrm{Cu}$. Guided by the cis/trans-nomenclature to describe alkene geometry, we herein also use the trans and cis terminology to specify the surface adsorbed biasamino-Cu-complexes. In the trans-isomer, the protons of the amino ligands are trans-oriented to each other whereas in the ciscomplex the protons of the amino ligands are oriented in cis configuration to each other. As the major oligomeric structure formed on a hot $\mathrm{Cu}(111)$ surface we found an all trans-configured coordination polymer revealing that oligmerization occurred with high trans-selectivity. The stability of the coordination polymers is remarkably high. Chains could be mechanically manipulated by the STM tip without losing their shape (Fig. $2 \mathrm{a}-\mathrm{c}$ ). The interaction of a $\mathrm{Cu}$ built-in atom of the oligomer with the $\mathrm{N}$ atom is much stronger than that with the metal substrate. For example, an oligomer containing $7 \mathrm{Cu}$ atoms was readily manipulated by pushing from one edge without destroying the polymeric structure. This means that the weakest bond in the system (likely the $\mathrm{Cu}-\mathrm{N}$ bond) is much stronger than the interaction of the all oligomer with its $7 \mathrm{Cu}$ atoms with the substrate. A strong interaction within the oligomers and weak interaction of the oligomer with the substrate gives also the possibility to elastically bend the coordination bonds (Fig. 2b). It was interesting that after manipulation the oligomer

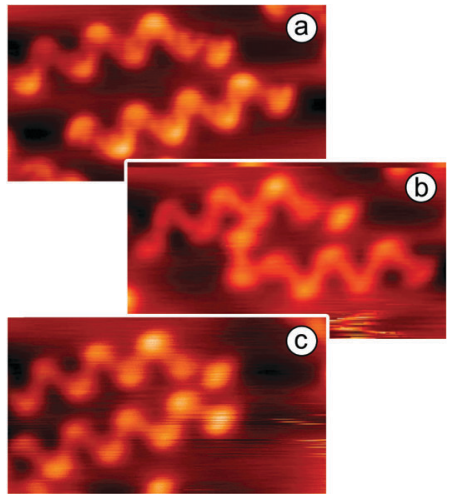

Fig. 2 Sequence of STM pictures showing manipulation of the DAN-Cu polymer by an STM tip. (a) All-trans coordination polymers. (b) Bent oligomer after pushing with the tip from one edge. (c) Manipulation of the single chain and return to the original shape after manipulation. Pictures: -2 V, 20 pA, manipulation: -2 V, 500 pA.

returned to its original lowest energy structure revealing shape memory behavior (Fig. 2c).

Polymerization of 1,4-diaminonaphthalene at $\mathrm{Cu}(110)$ : when DAN molecules were deposited on $\mathrm{Cu}(110)$ at room temperature in vacuum they form well-ordered structures where the organic molecules interact via hydrogen bonding. Heating of the substrate to $420 \mathrm{~K}$ leads to desorption of most DANs, but some of them formed short oligomers. As for the $\mathrm{Cu}(111)$ case discussed above, better results were achieved when the organic molecules were directly deposited on a hot $\mathrm{Cu}(110)$ surface. Polymer chains were formed, 
but interestingly, the shape of most oligomers differs significantly from the shape obtained for DAN-polymerization at $\mathrm{Cu}(111)$ where most of the polymers were generated with trans-configuration leading to a zig-zag type shape of the chain. However, at $\mathrm{Cu}(110)$ the largest part of the monomers is connected with alternating trans-cis-trans-cis relative configuration providing a U-shape type structure (Fig. 1b). One can clearly identify a minor fraction which polymerized with trans-configuration leading to a zig-zagtype oligomer.

Polymerization of 1,4-diaminonaphthalene at $\mathrm{Cu}(100)$ : DAN monomers were deposited at room temperature at $\mathrm{Cu}(100)$ providing a submonolayer with random distribution of the molecules. DAN did not form ordered or well packed islands. Differences in selfassembled monolayers between $\mathrm{Cu}(111), \mathrm{Cu}(110)$ and $\mathrm{Cu}(100)$ are caused by different periodicity and symmetry of these surfaces. Heating of the substrate containing physisorbed DAN molecules to $390 \mathrm{~K}$ provided tetramers with rectangular shape at high yield (Fig. 1c). The build-up of cyclic tetramers is a result of a highly diastereoselective all-cis-amino-Cu complex formation. The suggested chemical structure is shown below. For comparison with the $\mathrm{Cu}(111)$ and $\mathrm{Cu}(110)$ cases we also deposited DANs directly at a hot $\mathrm{Cu}(100)$ surface. For this substrate the hot and cold deposition procedures afforded similar results. Only a small amount of the molecules was desorbed during heating likely due to faster reaction and also due to stronger interaction of the monomer with the $\mathrm{Cu}$ substrate. To a small extent, the formation of cyclic tetramers was also observed at the previous $\mathrm{Cu}(110)$ substrate (Fig. 1b). To get a better picture of the selectivity of DAN oligomerization as a function of the substrate, we analyzed the number of trans and cis configured naphthylNH-Cu-NHnapthyl complexes extracted from various STM pictures which allowed us to gain statistical information on the trans/ cis-selectivity as a function of the $\mathrm{Cu}$ substrate. On the $\mathrm{Cu}(111)$ surface trans-configured bisamino-Cu-complexes occurred with $85 \%$ abundance A near complete cis-selectivity was observed for $\mathrm{Cu}(100)$ where almost all complexes (99\%) were formed as cisisomers. $\mathrm{Cu}(110)$ results in an intermediate state with the trans to cis complexes in a $66 \%$ to $34 \%$ ratio.

Theoretical investigations: based on STM data we proposed possible configurations of the various Cu-DAN-oligomers (Fig. 3), which were in good agreement with the experimentally observed structures. In the all-trans-configured oligomer identified as a zig/zag-shaped system on $\mathrm{Cu}(111)$, the $\mathrm{Cu}$-adatoms are lined up with a calculated distance of $0.75 \mathrm{~nm}$ which is in very good agreement with the experimentally determined value $(0.75 \mathrm{~nm})$. Metal atom chains are parallel to the three main symmetry axes $(\langle 0,1,-1\rangle,\langle-101\rangle$, and $\langle-110\rangle)$ of the $\mathrm{Cu}(111)$ substrate which forms the polymer mostly parallel to these three directions (see main chains in Fig. 1c). This also fits in to the theoretical model because structure can be easily rotated by $60^{\circ}$ to get the same adsorption geometry. For the $\mathrm{Cu}(110)$ substrate the experimentally observed U-shape oligomer occurred with some zig/zag shape oligomer similar to previous structure. In this case, the $\mathrm{Cu}$-adatoms appear to be highly regular with a distance of $0.79 \mathrm{~nm}$ from each other and form a zig/zag relative arrangement. In some cases all metal adatoms can lie in line along $\langle 3,3,2\rangle$ axes or its mirror direction $\langle 3,3,-2\rangle$ marked by red arrows (Fig. 4).
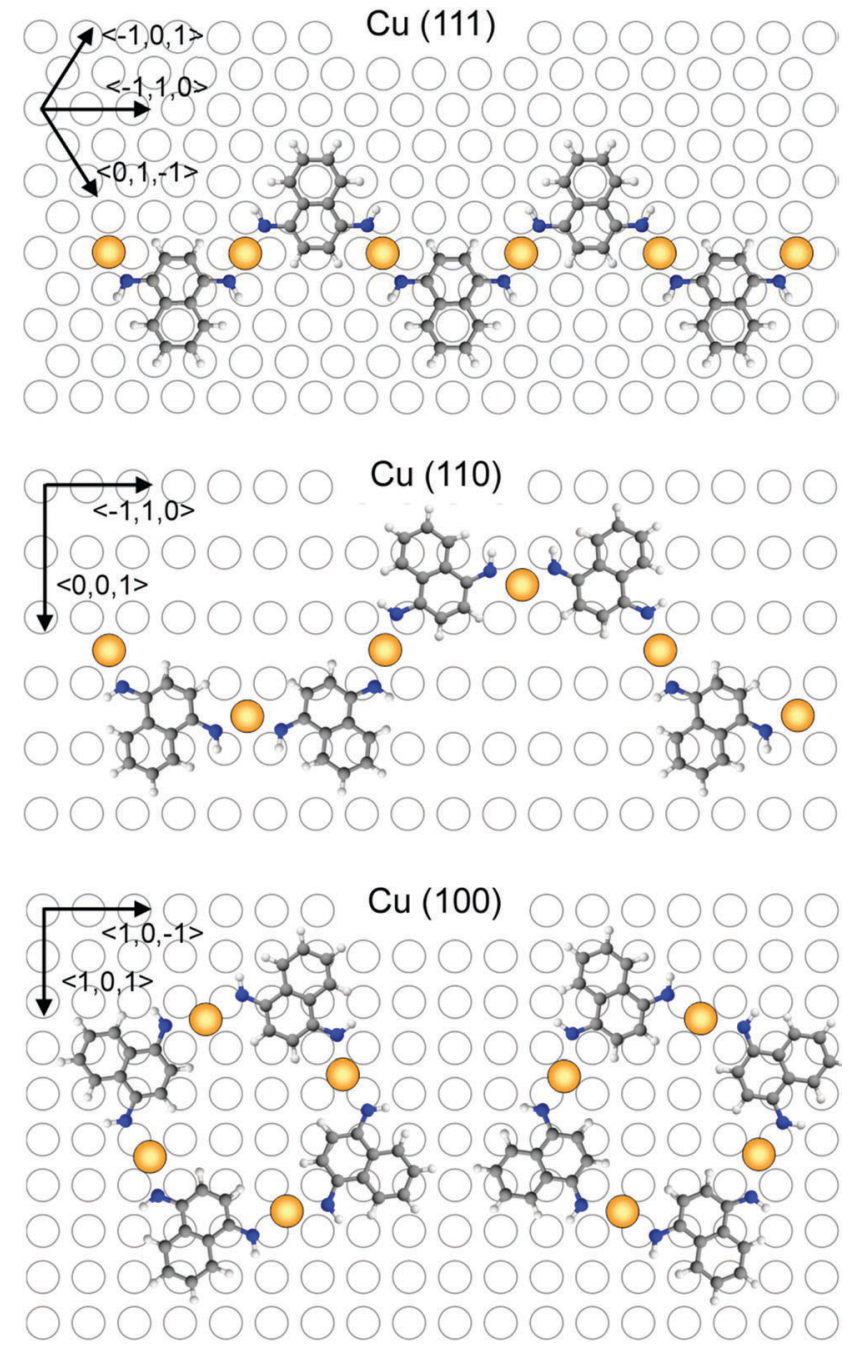

Fig. 3 Adsorption geometry of the DAN-Cu polymer at different Cu substrate planes.

When all $\mathrm{Cu}$ adatoms are parallel to this axis it effects only the trans substitution of the DAN molecules. When adsorption of the adatoms is not linear and it changes between these axes (dotted arrow) it causes the substitution of next DAN molecule in cis configuration. This substitution and growth mechanism are random which are clearly visible in the large area (Fig. 1b) and it fits well to the proposed model. Cis substitution can only occur parallel to the $\langle-1,1,0\rangle$ direction when two DAN molecules are mirrored in $\langle 0,0,1\rangle$ axes. Interestingly, whereas for the transconfiguration the $\mathrm{Cu}$-adatom lies in line in the middle of the two $\mathrm{N}$-atoms of the amino ligand (angle $\mathrm{N}-\mathrm{Cu}-\mathrm{N}=180^{\circ}$ ), in the cisconfigured complex the $\mathrm{N}-\mathrm{Cu}-\mathrm{N}$ angle is smaller $\left(120^{\circ}\right)$. This bending of the complex leads to an oligomeric structure where all distances between the $\mathrm{Cu}$-adatoms are very similar (theory: $0.79 \mathrm{~nm}$, experiment: $0.81 \mathrm{~nm}$ ) with main trans-cis-trans-cis alternating configurations. A smaller angle $\left(150^{\circ}\right)$ was also observed for the cis-complexes on $\mathrm{Cu}(100)$ where theory predicts the rectangular tetrameric structures. In this case there are two theoretical configurations on the surface which are their mirror reflection (mirror plane is parallel to one of the symmetry axes of 

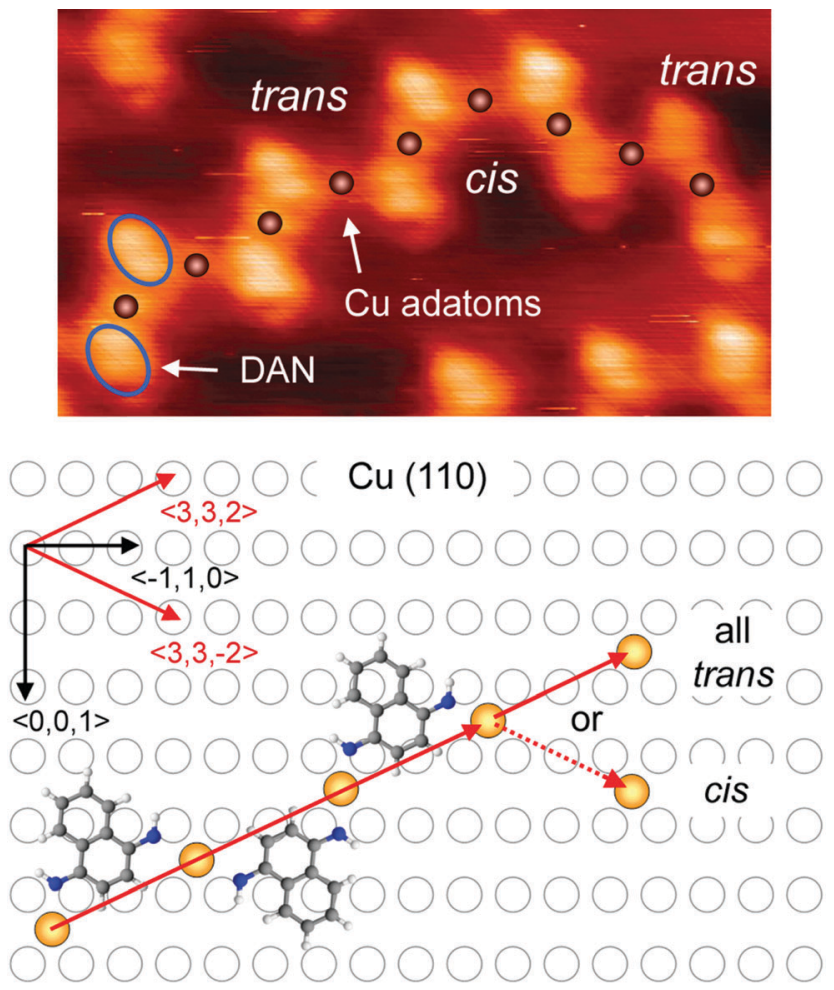

Fig. 4 All-trans adsorption geometry of the DAN-Cu polymer at the $\mathrm{Cu}(110)$ substrate plane. Red arrows indicate possible places of adsorption Cu adatoms in vacancy along one of the crystallographic directions $(\langle 3,3,2\rangle$ or $\langle 3,3,-2\rangle)$.

the substrate $\langle 1,0,-1\rangle$ or $\langle 1,0,1\rangle)$. Counting both of these configurations on several pictures gives a 50:50 ratio and information that the energy of adsorption and geometry at the substrate are exactly the same is in very good agreement with the proposed structure. Also the distance between $\mathrm{Cu}$ adatoms is in good agreement with the theoretical model (theory: $0.85 \mathrm{~nm}$, experiment: $0.9 \mathrm{~nm}$ ). Comparing optimal temperatures for the reaction, we discovered that reaction can easily occur at $\mathrm{Cu}(111)$ and $\mathrm{Cu}(100)$ substrates (390-400 K). Creation of the polymers at the $\mathrm{Cu}(110)$ surface needs $20 \mathrm{~K}$ higher temperature. Probably it is caused by higher stability of the $\mathrm{Cu}$ atom in the subsurface region and higher energy of its diffusion which is necessary to create longer polymer chains.

In summary we observed that different crystallographic planes of the same substrate $[\mathrm{Cu}(111), \mathrm{Cu}(110)$ and $\mathrm{Cu}(100)]$ can influence the nature of polymers. Growth of the polymer at the $\mathrm{Cu}(111)$ substrate provides mostly trans conformation while $\mathrm{Cu}(100)$ gives only cis conformation. $\mathrm{Cu}(110)$ has both of these properties and trans and cis conformation can exist on the surface with random distribution or also regular trans-cis-trans-cis order. This strong selectivity of the crystallographic plane of $\mathrm{Cu}$ - surface orientations with respect to the final product structures can be helpful to optimize catalytic processes and isomerization at surfaces. We also showed by manipulation of the polymer chains that coordination bonded systems $\mathrm{N}-\mathrm{Cu}-\mathrm{N}$ are very stable when metal atoms are extracted from the surface while their interaction with the metal substrate is weak (compared to the interaction in the polymer chain).

We would like to thank the Deutsche Forschungsgemeinschaft (TRR 61, project B3) for financial support.

\section{References}

1 (a) J. Cai, P. Ruffieux, R. Jaafar, M. Bieri, T. Braun, S. Blankenburg, M. Muoth, A. P. Seitsonen, M. Saleh, X. Feng, K. Mullen and R. Fasel, Nature, 2010, 466, 470-473; (b) D. F. Perepichka and F. Rosei, Science, 2009, 323, 216-217; (c) M. Matena, T. Riehm, M. Stähr, T. A. Jung and L. H. Gade, Angew. Chem., Int. Ed., 2008, 47, 2414-2417; (d) A. C. Marele, R. MasBallesté, L. Terracciano, J. Rodríguez-Fernández, I. Berlanga, S. S. Alexandre, R. Otero, J. M. Gallego, F. Zamora and J. M. GómezRodríguez, Chem. Commun., 2012, 48, 6779-6781; (e) M. Treier, N. V. Richardson and R. Fasel, J. Am. Chem. Soc., 2008, 130, 14054-14055; $(f)$ I. Q. Zhang, N. Kepcija, M. Kleinschrodt, K. Diller, S. Fischer, A. C. Papageorgiou, F. Allegretti, J. Bjork, S. Klyatskaya, F. Klappenberger, M. Ruben and J. V. Barth, Nat. Commun., 2012, 3, 1286; $(g)$ D. Zhong, J. H. Franke, S. K. Podiyanachari, T. Blomker, H. Zhang, G. Kehr, G. Erker, H. Fuchs and L. Chi, Science, 2011, 334(6053), 213-216; (h) J. A. Lipton-Duffin, O. Ivasenko, D. F. Perepichka and F. Rosei, Small, 2009, 5(5), 592-597; (i) A. Ciesielski, M. El Garah, S. Haar, P. Kovaricek, J. M. Lehn and P. Samori, Nat. Chem., 2014, 6, 1017-1023.

2 (a) S. Haq, F. Franke, M. S. Dyer, M. Persson, P. Iavicoli, D. B. Amabilino and R. Raval, J. Am. Chem. Soc., 2011, 133, 12031-12039; (b) M. Bieri, S. Blankenburg, M. Kivala, C. A. Pignedoli, P. Ruffieux, K. Mulen and R. Fasel, Chem. Commun., 2011, 47, 10239-10241; (c) Q. Li, J. R. Owens, C. Han, B. G. Sumpter, W. Lu, J. Bernholc, V. Meunier, P. Maksymovych, M. Fuentes-Cabrera and M. Pan, Sci. Rep., 2013, 3(2102), 1-6; (d) H. Zhang, J. H. Franke, D. Zhong, Y. Li, A. Timmer, O. D. Arado, H. Monig, H. Wang, L. Chi, Z. Wang, K. Mullen and H. Fuchs, Small, 2014, 10(7), 1361-1368; (e) J. Eichhorn, T. Strunskus, A. Rastgoo-Lahrood, D. Samanta, M. Schmittel and M. Lackinger, Chem. Commun., 2014, 50, 7680-7682.

3 (a) D. Kuhne, F. Klappenberger, R. Decker, U. Schlickum, H. Brune, S. Klyatskaya, M. Ruben and J. V. Barth, J. Am. Chem. Soc., 2009, 131, 3881-3883; (b) M. Marschall, J. Reichert, A. Weber-Bargioni, K. Seufert, W. Auwarter, S. Klyatskaya, G. Zoppellaro, M. Ruben and J. V. Barth, Nat. Chem., 2010, 2, 131-137; (c) J. Liu, T. Lin, Z. Shi, F. Xia, L. Dong, P. N. Liu and N. Lin, J. Am. Chem. Soc., 2011, 133, 18760-18766; (d) D. Heim, D. Ecija, K. Seufert, W. Auwarter, C. Aurisicchio, C. Fabbro, D. Bonifazi and J. V. Barth, J. Am. Chem. Soc., 2010, 132, 6783-6790; (e) U. Schlickum, R. Decker, F. Klappenberger, G. Zoppellaro, S. Klyatskaya, M. Ruben, I. Silanes, A. Arnau, K. Kern, H. Brune and J. V. Barth, Nano Lett., 2007, 7(12), 3813-3817; ( $f$ ) A. Langner, S. L. Tait, N. Lin, C. Rajaduari, M. Ruben and K. Kern, Proc. Natl. Acad. Sci. U.S.A., 2007, 104(46), 17927-17930.

4 (a) V. Barth, J. Weckesser, N. Lin, A. Dmitriev and K. Kern, Appl. Phys. A: Mater. Sci. Process., 2003, 76, 645-652; (b) N. A. Kautz and S. A. Kandel, J. Am. Chem. Soc., 2008, 130(22), 6908-6909; (c) F. Li, L. Tang, W. Zhou and Q. Guo, J. Am. Chem. Soc., 2010, 132, 13059-13063; (d) G. Pawlin, K. L. Wong, D. Kim, D. Sun, L. Bartels, S. Hong, T. S. Rahman, R. Carp and M. Marsella, Angew. Chem., Int. Ed., 2008, 47, 8442-8445.

5 D. Grumell, B. Wurster, S. Stepanow and K. Kern, Nat. Commun., 2013, 4, 2904.

6 (a) N. Abdurakhmanova, T. C. Tseng, A. Langner, C. S. Kley, V. Sessi, S. Stepanov and K. Kern, Phys. Rev. Lett., 2013, 110, 027202; (b) P. Gambardella, S. Stepanow, A. Dimitriev, J. Honolka, F. M. F. de Groot, M. Lingenfelder, S. S. Gupta, D. D. Sarma, P. Bencok, S. Stanescu, S. Clair, S. Pons, N. Lin, A. P. Seitsonen, H. Brune, J. V. Barth and K. Kern, Nat. Mater., 2009, 8, 189-193.

7 L. Bartels, Nat. Chem., 2010, 2, 87-95.

8 L. Vitali, G. Levita, R. Ohmann, A. Comisso, A. De Vita and K. Kern, Nat. Mater., 2010, 9, 320-323.

9 (a) M. Stohr, M. Wahl, C. H. Galka, T. Riehm, T. A. Jung and L. H. Gade, Angew. Chem., Int. Ed., 2005, 44, 7394-7398; (b) H. Kong, Q. Sun, L. Wang, Q. Tan, C. Zhang, H. Sheng and W. Xu, ACS Nano, 2014, 8(2), 1804-1808. 